\title{
Cross-sectional assessment of workers with repeated exposure to chlorine over a three year period
}

\author{
D. Gautrin*, C. Leroyer*, J. L'Archevêque*, J-G. Dufour**, D. Girard+', J-L. Malo*
}

\begin{abstract}
Cross-sectional assessment of workers with repeated exposure to chlorine over a three year period. D. Gautrin, C. Leroyer, J. L'Archevêque, J-G. Dufour, D. Girard, J-L. Malo. (C) ERS Journals Ltd 1995.

ABSTRACT: Airflow obstruction has been described in workers who experienced symptoms after acute exposure to chlorine. Persistent bronchial hyperresponsiveness has also been assessed, but mainly in case studies. In this cross-sectional study, we have assessed the relationship between inhalational accidents ("puffs") involving chlorine and persistent symptoms as well as hyperresponsiveness in 239 out of 255 at-risk workers $(94 \%)$.

No relationship was found between persistent symptoms and the exposure variables studied. Forced vital capacity (FVC) was higher in subjects who had had no symptoms after a "puff", compared with those who had experienced mild symptoms. Forced expiratory volume in one second (FEV1) and FVC were significantly lower in subjects who experienced more than 10 puffs with mild symptoms than in subjects who reported no symptomatic puff. The presence of bronchial hyperresponsiveness was not related to exposure, but the methacholine dose-response slope showed a tendency to increased bronchial responsiveness with increased exposure. A significant difference was shown in subjects who experienced more than 10 puffs with mild symptoms.

In this group of workers, repeated exposure to chlorine with acute respiratory symptoms was associated with a slight but significant reduction in expiratory flow rates, together with an increase in bronchial responsiveness, without long-term symptoms.
\end{abstract}

Eur Respir J., 1995, 8, 2046-2054.
*Dept of Chest Medicine, Hôpital du SacréCoeur, Montreal, Canada. **occupamed,

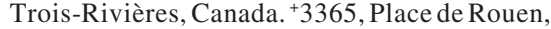
Trois-Rivières, Canada.

Correspondence: D. Gautrin, Dept of Chest Medicine, Sacré-Coeur Hospital, 5400 Gouin West, Montreal, Canada H4J 1C5

Keywords: Bronchial diseases, bronchial provocation tests, irritants, occupational exposure, reactive airways dysfunction syndrome

Received: February 231995

Accepted after revision August 191995

This study was partially funded by the Association pulmonaire du Québec, the Fonds de recherche en santé du Québec and the Centre québécois d'excellence en santé respiratoire. JLM is a research fellow with the Fonds de la recherche en santé du Québec and the Université de Montréal School of Medicine. DG is a research fellow with the BoehringerIngelheim Foundation and the Université de Montréal School of Medicine.
The health effects of inhalational chlorine toxicity were initially described during and after World War I [1, 2]. After a single acute exposure, conjunctival and nasal irritation, acute pneumonitis, pulmonary oedema and transient bronchospasm can occur, as reviewed by DAS and BLANC [3]. Complete functional recovery in terms of spirometry and lung volumes is usually observed $[4,5]$, although bronchial hyperresponsiveness can persist $[6,7]$. These inhalational accidents can lead to the so-called reactive airways dysfunction syndrome (RADS), or irritant-induced asthma, as defined by BROOKS and co-workers [8,9]. The chronic respiratory effects of repeated chlorine gas exposure have recently been examined. Studies were conducted on workers employed in pulpmills, where they were exposed to chlorine [10-12]. Exposure resulted in an increase in chronic respiratory symptoms and a decrease in pulmonary function tests. The chronic effects of chlorine can be caused by repeated accidental short-term inhalations causing acute symptoms and/or by chronic exposure to chlorine at low levels [10-12].

Epidemiological studies conducted on workers exposed to chlorine included respiratory questionnaires and spirometry. Only rarely have studies included anassessment of bronchial responsiveness. This point is relevant because exposure to chlorine can induce a syndrome of airway irritation with persistent asthma-like symptoms and bronchial hyperresponsiveness that can resemble occupational asthma [9]. The aim of this study, therefore, was to relate the occurrence of accidental acute chlorine exposure and immediate respiratory symptoms to current respiratory symptoms, spirometry and airway responsiveness, among workers who had undergone repeated accidental chlorine inhalation over a 3 year period. We hypothesized that there would be not only clinical and functional abnormalities but, even more so, bronchial hyperresponsiveness associated with acute chlorine exposure causing symptoms.

\section{Methods}

\section{Subjects and study design}

All 255 workers at risk of accidental chlorine exposure were asked to participate in the study. They worked in a plant that had started operations in 1989. No significant change in processes, equipment or work practices had 
occurred during the 3 year period. Workers could have experienced acute inhalational accidents in any area of the plant: ore smelting (dissolution with hydrochloric acid), dehydration, electrolysis leading to isolation of chlorine, or foundry. Workers from the technical maintenance and hydrochloric acid synthesis areas could also be exposed.

This cross-sectional study focused on the relationship between acute high-level exposure and persistent bronchial abnormalities. Comparisons were made between subgroups of workers according to the frequency of acute exposure and the intensity of immediate symptoms. The study protocol was approved by the Hôpital du SacréCoeur Ethics Committee and written consent was obtained from all participants. Data were collected by a trained nurse and two medical technologists at the workplace during 3 months in the autumn of 1992.

\section{Questionnaires}

A French adaptation version of the International Union against Tuberculosis and Lung Diseases questionnaire [13] was administered by the nurse. This questionnaire assessed the presence of chronic respiratory symptoms at the time of the study. The presence of chronic bronchitis and of personal asthma were also established, and a complete smoking history was recorded.

A second questionnaire focused on accidental exposure to chlorine, $\mathrm{HCl}$, or other irritant gases (exposures to chlorine alone or with other irritants are referred to as "puffs"), in order to evaluate the occurrence of puffs, the number of events per year, the year of the last puff, the nature of the irritant(s), and the occurrence and intensity of respiratory symptoms after inhaling puffs (expressed as absent, mild or significant). An accidental chlorine exposure was considered to have taken place when workers responded positively to the following question: "Have you ever had an episode of high acute exposure to chlorine ("puff")?". Additional data regarding precise occupational history, including area of work and duration, were provided. Finally, information was obtained on possible previous occupational exposure to irritants.

\section{First-aid reports}

In the case of accidental exposure followed by significant symptoms, the factory medical unit provided firstaid care. Data from each individual first-aid report were available and were collected, in order to further assess acute chlorine exposure events and information bas.

\section{Pulmonary function testing}

Spirometric measurements were performed according to the criteria of the American Thoracic Society using a Collins-type spirometer (WE Collins, Braintree, MA, USA) [14]. The following measurements were performed and derived: forced expiratory volume in one second (FEV1), forced vital capacity (FVC), the FEV1/FVC ratio and forced mid-expiratory flow (FEF25-75\%); the latter being recorded from the expiratory effort with the highest FEV1 and FVC sum. Results were expressed as a percentage of the predicted value. Reference values for spirometry were obtained from KNUDSON et al. [15].

\section{Bronchial responsiveness}

Methacholine challenge tests were performed according to a standardized methodology with a Wright nebulizer (Aerosol Medical Ltd, Colchester, Essex, UK) (output $\left.0.14 \mathrm{~mL} \cdot \mathrm{min}^{-1}\right)$, and methacholine inhaled at tidal volume breathing for 2 min [16]. An abbreviated method, with a starting concentration of $2 \mathrm{mg} \cdot \mathrm{mL}^{-1}$, was applied in subjects with lung function results within normal range and no past history suggestive of asthma [17]. The test ended at the concentration of $32 \mathrm{mg} \cdot \mathrm{mL}^{-1}$ if a $20 \%$ fall in FEV1 had not been reached.

Challenge tests were performed by medical technologists under close supervision by the occupational physician. The test was postponed for 2 weeks in subjects suffering from a current acute upper airway infection.

\section{Environmental assessment}

An air monitoring survey had been conducted by the factory's industrial hygienist. Chlorine concentrations were collected using the same device (Metrosonics pm7700*) that performed analysis on a continuous basis. Two area samplings were performed in May 1992 in the foundry area, and six personal samplings from October 1991 to May 1992, both in the electrolysis and foundry areas; the mean time of daily analysis was $361 \mathrm{~min}$ both for area and personal sampling (range 31-684 min). Current portable personal apparatus does not allow for quantitative assessment of peak chlorine inhalational aaccidents. These devices can evaluate $95 \%$ of chlorine level, but the reading is accurate only if there has been continuous exposure for $3 \mathrm{~min}$. In case of acute exposure, workers usually leave the contaminated area before this time. In addition, they are requested to put on their portable face-masks immediately.

\section{Data analysis}

Dose-response curves to methacholine were drawn on a semilogarithmic noncumulative scale. The measurable concentration of methacholine provoking a $20 \%$ reduction in FEV1 (PC20) was interpolated on the individual curve. Three parameters were considered for analysis: a PC20 $\leq 16 \mathrm{mg} \cdot \mathrm{mL}^{-1}$ defined significant bronchial hyperresponsiveness [18]; a measurable PC20 $\leq 32 \mathrm{mg} \cdot \mathrm{mL}^{-1}$; and the slope of the dose-response curve. The latter was calculated in order to study a quantitative, continuous variable, as is recommended for population studies [19]. 
The dose-response slope was expressed by the percentage decline in FEV1/dose, where decline was expressed as a positive value and where dose in $\mu \mathrm{mol}$ was defined as the final cumulative methacholine dose administered (conversion from $\mathrm{mg}$ of bromide methacholine to $\mu \mathrm{mol}$, using a corrective factor of 5.116 [17]). As the slope distribution was not normal ( $\mathrm{p}<0.0001$, Lilliefors test of normality), a logarithmic transformation of this ratio was then used. Higher positive values corresponded to more pronounced airway responsiveness. Significant hyperresponsiveness, together with a positive response to the question, "Have you ever had asthma?", were required to define a diagnosis of current personal asthma.

Several indices of exposure were generated from the questionnaire. The primary exposure variables were accident report; occurrence of puffs as reported in the questionnaire and classified according to the occurrence of immediate symptoms (absent, mild, significant); number of puffs with mild symptoms $(0,1-5,6-10,>10)$. The secondary exposure variables considered as associated factors were the occurrence of the last symptomatic puff in 1992 (year of the study) or before; and previous occupational irritant exposure, including exposure to chlorine and other irritants (gas and smoke). Tobacco intake (never, ever), pack-years $(<20, \geq 20)$, and personal asthma were considered as potential confounders.

All questionnaire responses and lung function results were coded, key-punched, verified and registered in computer files. Analyses were performed using the (SPSS)/PC+ statistical software package (Chicago, IL, USA). Analyses were accomplished using Chi-squared, one-way and twoway analysis of variance (ANOVA) as appropriate. The significance of the differences found between means was tested using the least significant difference (LSD) procedure. Multivariate logistic regression analyses were also performed to evaluate the effects of potential risk factors on the presence of hyperresponsiveness. A p-value equal to or less than 0.05 was considered significant.

\section{Results}

Demographic characteristics, work and smoking history

A total of 239 (94\%) out of 255 workers at-risk, 237 males and 2 females, participated in the study. Of the remaining 16 workers, 15 refused to participate and one was absent due to a chronic illness. The mean age was 33 yrs (range 18-49 yrs). One hundred and eight workers reported no smoking history, and 131 either current smoking or a past history of tobacco use. At the time of the study, 18 worked in the smelting area, 50 in dehydration, 54 in electrolysis, 64 in the foundry, 11 in synthesis, 32 in maintenance activities and 10 in other areas.

\section{Accidental gassing incidents}

From the time the plant started production, 42 workers reported at least one gassing accident to the first-aid unit. Three of these workers had left the factory before the study
Table 1. - Gassing incidents reported in the questionnaire by workers between 1989 and 1992 by working area and by type of gas

\begin{tabular}{|c|c|c|}
\hline & \multicolumn{2}{|c|}{ Number of incidents } \\
\hline & $\begin{array}{l}\text { With mild } \\
\text { symptoms } \\
(\mathrm{n}=527)\end{array}$ & $\begin{array}{c}\text { With significant } \\
\text { symptoms } \\
(\mathrm{n}=44)\end{array}$ \\
\hline \multicolumn{3}{|c|}{$\begin{array}{l}\text { Working area - number of subjects who ever worked in } \\
\text { area }\end{array}$} \\
\hline Dehydration $(n=73)$ & 104 & 3 \\
\hline Smelting area $(n=38)$ & 66 & 3 \\
\hline Synthesis $(n=38)$ & 59 & 9 \\
\hline Electrolysis $(n=100)$ & 159 & 23 \\
\hline Foundry $(n=90)$ & 87 & 3 \\
\hline Electrical maintenance $(n=5)$ & 7 & - \\
\hline Mechanical maintenance $(n=20)$ & 16 & 3 \\
\hline Other maintenance $(n=34)$ & 15 & - \\
\hline \multicolumn{3}{|l|}{ Other areas } \\
\hline Intervention $(n=5)$ & 6 & - \\
\hline Health and Safety $(n=5)$ & 4 & - \\
\hline Laboratory $(n=3)$ & 2 & - \\
\hline Environment $(n=2)$ & 2 & - \\
\hline \multicolumn{3}{|c|}{ Type of gas - frequency and \% of reported incidents } \\
\hline Chlorine & $240(46)$ & $31(71)$ \\
\hline $\mathrm{HCl}$ & $165(31)$ & $9(21)$ \\
\hline $\mathrm{Cl}+\mathrm{HCl}$ & 85 (16) & $1(2.3)$ \\
\hline $\mathrm{Cl}+\mathrm{HCl}+$ ammoniac & $1(0.2)$ & - \\
\hline $\mathrm{Cl}+\mathrm{Mg}$ & $4(0.8)$ & - \\
\hline $\mathrm{Cl}+\mathrm{SF}_{6}$ & $18(3.4)$ & - \\
\hline $\mathrm{Cl}+\mathrm{S}$ & $2(0.4)$ & - \\
\hline $\mathrm{HCl}+\mathrm{MgO}$ & $5(1.0)$ & - \\
\hline $\mathrm{H}_{2} \mathrm{~S}$ & - & $2(4.6)$ \\
\hline $\mathrm{SF}_{6}$ & $4(0.8)$ & $1 \quad(2.3)$ \\
\hline$S^{\circ}$ & $2(0.4)$ & - \\
\hline Unknown & $1(0.2)$ & - \\
\hline
\end{tabular}

Values in parentheses are percentages of total events of exposure in each group.

started. Of the 39 workers currently employed in the plant, four did not participate in the study: one was absent because of chronic illness and three refused. The proportion of first-aid unit reported gassing incidents among participants was $15 \%$ (35 out of 239 ), compared with $25 \%$ among nonparticipants (4 out of 16); this difference was not statistically significant $(\mathrm{p}=0.22$, Fisher's exact test). No significant peak in occurrence of these accidents was observed during the period studied. In $98 \%$ of accidental exposures, chlorine was reported as the gas involved, either alone or in combination with another gas (table 1). All reported results are restricted to those incidents. Questionnaire-reported accidental gassing events with immediate significant symptoms occurred in 38 workers: only three subjects reported a puff followed by immediate significant symptoms that did not lead to a first-aid visit. One hundred and fifty three workers reported a puff occurrence with mild symptoms, and 45 without symptoms. Three workers denied having ever experienced any acute exposure. Among subjects reporting a puff exposure with mild symptoms, 65 (27\%) experienced more than 10 incidents. The last symptomatic puff occurred in 1992 for 136 workers (57\%). 
Table 2. - Persistent respiratory symptoms, according to accidental exposure to chlorine and tobacco use (frequency and percentages)

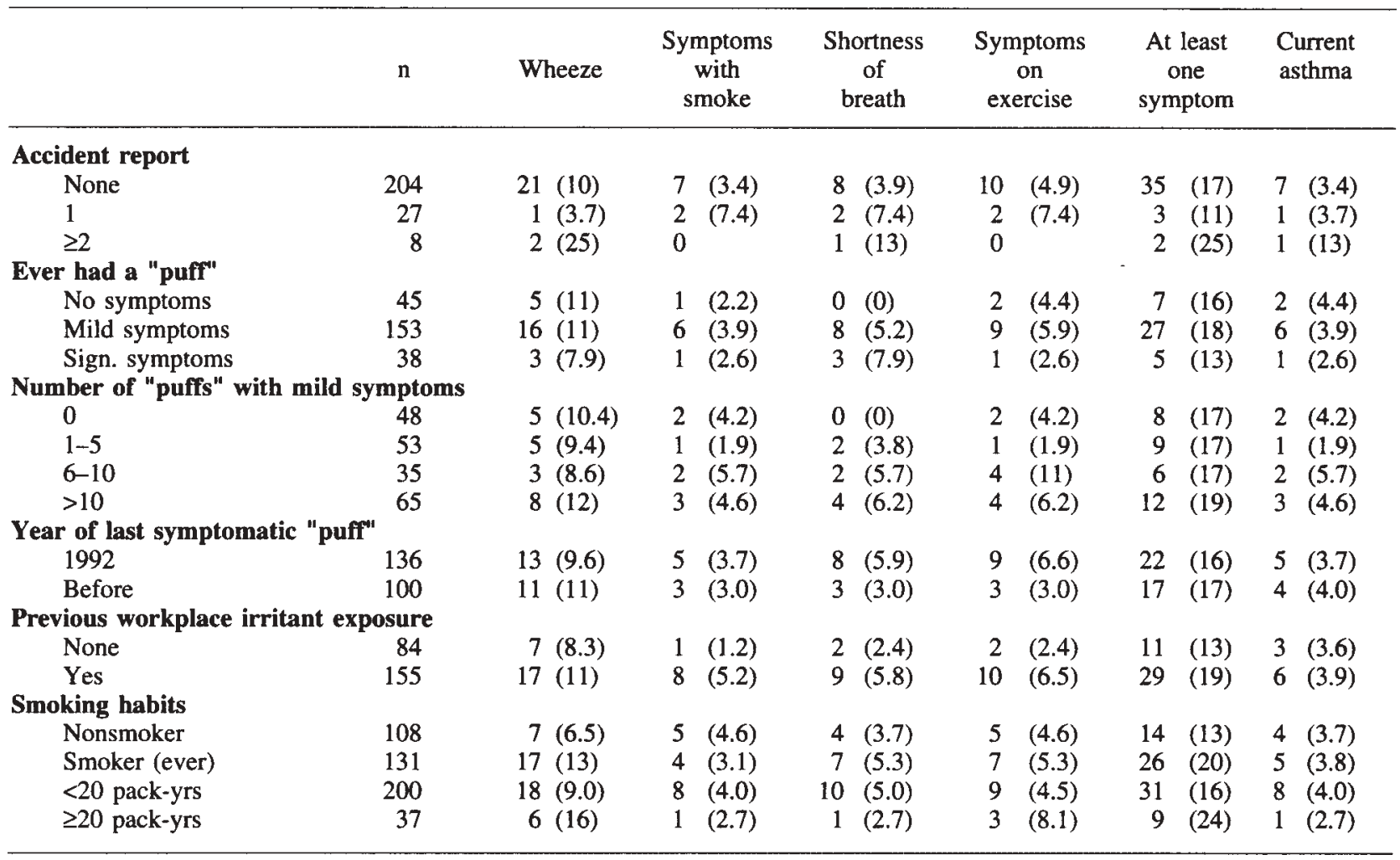

Values in parentheses are percentages of total number of subjects in exposure category. Sign.: significant.

\section{Current respiratory symptoms}

Three workers reported symptoms of chronic bronchitis $(1.3 \%)$, and nine $(3.7 \%)$ were considered as suffering from current asthma; none of these mentioned any use of anti-inflammatory medication, but six asthmatic workers occasionally used inhaled bronchodilators.

A small proportion of workers complained of current respiratory symptoms. Forty workers $(17 \%)$ reported the presence of at least one current symptom: wheeze in 24 workers $(10 \%)$; bronchial symptoms following nonspecific irritant exposure in nine $(4 \%)$; shortness of breath in $11(5 \%)$ and symptoms on exercise in $12(5 \%)$. Table 2 shows the frequency of persistent respiratory symptoms according to exposure; we found no relationship between complaints of persistent symptoms and the exposure variables studied.

\section{Pulmonary function results}

All mean values were within normal range: mean FEV1 was $99 \%$ of predicted value (range $58-132 \%$ pred), mean FVC was $101 \%$ pred (range $75-133 \%$ pred), mean FEV1/FVC was $98 \%$ pred (range $77-112 \%$ pred), and mean $\mathrm{FEF} 25-75 \%$ was $94 \%$ pred (range $31-185 \%$ pred). The percentage of subjects with values $<80 \%$ predicted was 4.2 for FEV1 and 1.3 for FVC. The percentage of subjects with values $<40 \%$ predicted was 7.1 for FEF25-75\%.
Table 3 shows the results of the pulmonary function tests according to the exposure variables. FVC was significantly lower in the group that reported either mild symptoms or any (i.e. mild or significant) symptoms after an acute exposure, as compared with the nonsymptomatic workers. This difference remained significant after controlling for smoking. When considering workers that had ever smoked and nonsmokers separately, the FVC difference remained significant for the smokers only; in addition, FEV1 was significantly lower in the subgroup of smokers who reported immediate symptoms. There was interaction between previous irritant exposure and report of symptomatic acute exposure: among workers reporting a symptomatic puff, FVC was significantly lower when there was a past history of previous irritant exposure (99 vs $106 \%$ ).

Significant differences were also seen according to the number of self-reported puffs with mild symptoms (fig. 1): FEV1 and FVC were lower in workers reporting more than 10 puffs with mild symptoms, in comparison with those reporting no symptomatic puff. No interaction was shown between the number of puffs with mild symptoms and both secondary exposure variables and confounding variables (see Methods). In addition, FEV1/FVC ratio and FEF25-75\% were significantly lower in workers reporting more than 10 puffs, as compared with those reporting 1-5 and 6-10 puffs. When comparing workers reporting more than 10 puffs to all other categories pooled together, FEV1, FEV1/FVC and FEF25-75\% were significantly lower. These differences remained significant when controlling 
for tobacco intake and current asthma. Multivariate regression analysis was performed for each functional variable, including as explanatory variables the primary exposure variables studied (intensity of puff, number of puffs), the secondary exposure variables (year of last puff, previous irritant exposure), and the potential confounders; none of the independent variables reached the $p<0.05$ criteria for retention in the model. In any case, the regression model was inappropriate to predict the variations in lung function $\left(\mathrm{r}^{2}<1 \%\right)$.

Table 3. - Lung function results according to reported accidental exposure to chlorine gas, and tobacco use

\begin{tabular}{|c|c|c|c|c|c|}
\hline & $\mathbf{n}$ & $\begin{array}{l}\text { FEV } 1 \\
\% \text { pred }\end{array}$ & $\begin{array}{l}\text { FVC } \\
\% \text { pred }\end{array}$ & $\begin{array}{c}\text { FEV1/FVC } \\
\% \text { pred }\end{array}$ & $\begin{array}{c}\text { FEF25-75\% } \\
\% \text { pred }\end{array}$ \\
\hline \multicolumn{6}{|l|}{ Accident report } \\
\hline None & 204 & $99 \pm 11$ & $101 \pm 10$ & $98 \pm 6$ & $94 \pm 22$ \\
\hline 1 & 27 & $99 \pm 9$ & $102 \pm 7$ & $97 \pm 6$ & $90 \pm 20$ \\
\hline$\geq 2$ & 8 & $101 \pm 14$ & $103 \pm 9$ & $98 \pm 7$ & $103 \pm 38$ \\
\hline \multicolumn{6}{|l|}{ Ever had a "puff" } \\
\hline No symptoms & 45 & $101 \pm 12$ & $104 \pm 11$ & $100 \pm 6$ & $94 \pm 25$ \\
\hline Mild symptoms & 153 & $98 \pm 11$ & $100 \pm 10^{*}$ & $98 \pm 6$ & $93 \pm 21$ \\
\hline Sign. symptoms & 38 & $98 \pm 11$ & $101 \pm 8$ & $98 \pm 6$ & $93 \pm 25$ \\
\hline \multicolumn{6}{|c|}{ Number of "puffs" with mild symptoms } \\
\hline 0 & 48 & $101 \pm 12$ & $104 \pm 11$ & $97 \pm 6$ & $95 \pm 25$ \\
\hline $1-5$ & 53 & $99 \pm 11$ & $101 \pm 11$ & $99 \pm 6$ & $96 \pm 21$ \\
\hline $6-10$ & 35 & $100 \pm 9$ & $101 \pm 8$ & $99 \pm 5$ & $97 \pm 21$ \\
\hline$>10$ & 65 & $96 \pm 12^{\dagger}$ & $100 \pm 10^{\dagger}$ & $97 \pm 6 \pm 1$ & $89 \pm 21 \neq 1$ \\
\hline \multicolumn{6}{|c|}{ Year of last symptomatic "puff" } \\
\hline 1992 & 136 & $98 \pm 11$ & $100 \pm 9$ & $98 \pm 6$ & $94 \pm 24$ \\
\hline Before & 100 & $100 \pm 12$ & $102 \pm 11$ & $98 \pm 6$ & $93 \pm 21$ \\
\hline \multicolumn{6}{|c|}{ Previous workplace irritant exposure } \\
\hline None & 84 & $100 \pm 11$ & $102 \pm 10$ & $98 \pm 5$ & $93 \pm 23$ \\
\hline Yes & 155 & $98 \pm 11$ & $100 \pm 10$ & $98 \pm 6$ & $94 \pm 22$ \\
\hline \multicolumn{6}{|l|}{ Smoking habits } \\
\hline Nonsmoker & 108 & $99 \pm 10$ & $101 \pm 10$ & $98 \pm 5$ & $92 \pm 20$ \\
\hline Smoker (ever) & 131 & $98 \pm 12$ & $101 \pm 10$ & $98 \pm 6$ & $95 \pm 25$ \\
\hline$<20$ pack-yrs & 200 & $99 \pm 11$ & $101 \pm 10$ & $98 \pm 6$ & $94 \pm 21$ \\
\hline$\geq 20$ pack-yrs & 37 & $96 \pm 13$ & $100 \pm 10$ & $96 \pm 7$ & $91 \pm 29$ \\
\hline
\end{tabular}

Values arc presented as mean \pm SD. FEV1: forced expiratory volume in one second; FVC: forced vital capacity; FEF25-75\%: forced mid-expiratory flow. ${ }^{*}: \mathrm{p}<0.05$ in analysis of variance comparing "Mild" to "No" symptoms; ${ }^{\dagger}:$ comparing $>10$ to $0 ;{ }^{\ddagger}$ : comparing $>10$ to $1-5$; ${ }^{\text {It }}$ comparing $>10$ to $6-10$.
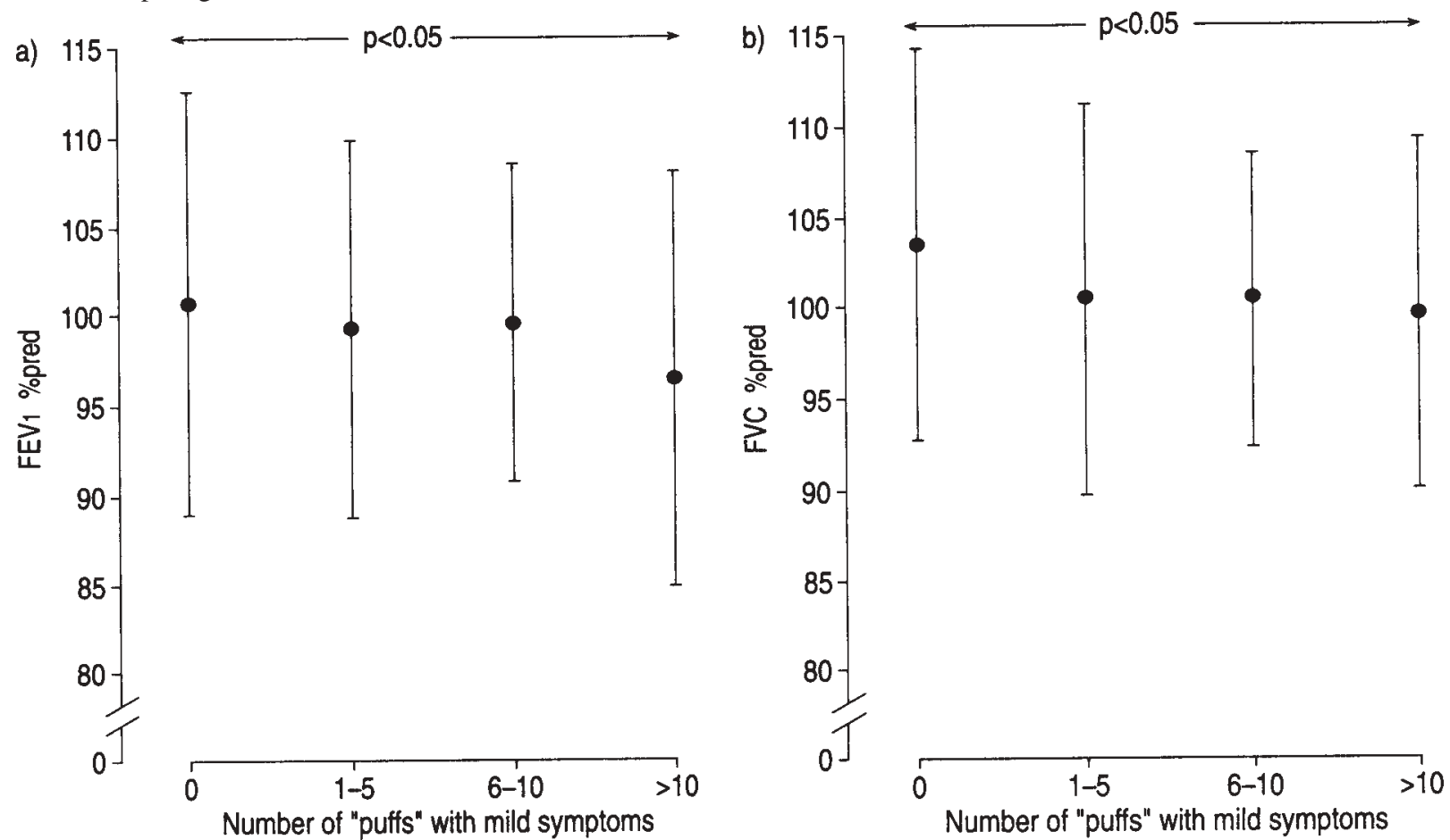

Fig. 1. - Mean and SD: a) FEV1 \% predicted; and b) FVC \% predicted, with the number of "puffs" with mild symptoms. FEV1: forced expiratory volume in one second; FVC: forced vital capacity. 


\section{Bronchial responsiveness}

Table 4 shows the results of methacholine challenge tests according to exposure and smoking. Analysis of the log dose-response slope in relation to the exposure variables indicated an overall tendency to increased airway responsiveness with increasing levels of exposure, expressed by the following variables: accident report, occurrence of puff and immediate symptoms, number of puffs. A significant difference was shown for the variable "number of puffs with mild symptoms", where population means overall were different. In addition, for the methacholine dose-response slope analysis, workers who experienced more than 10 puffs showed a more pronounced responsiveness than those who reported 1-5 puffs (fig. 2) or than workers from all other categories pooled together, in a contrast analysis. The differences between the population means of the log dose-response slope remained statistically significant after controlling for smoking and asthma. There was a significantly higher proportion of subjects with a measurable PC20 among workers who had reported twice or more to the first-aid unit because of inhalational accidents.

Logistic regression analyses were performed to assess the effect of categorical exposure variables (intensity of puff, number of puffs) on hyperresponsiveness expressed as measurable $\mathrm{PC} 20\left(\leq 32 \mathrm{mg} \cdot \mathrm{mL}^{-1}\right)$, using simple contrasts where the lowest exposure variable was considered as the reference level. The odds ratio for having had a puff with mild symptoms was 1.03 (95\% confidence interval $(95 \%$
CI) $0.3-4.1)$ and 2.02 (95\% CI 0.5-9) for a puff with significant symptoms. Among workers who experienced only mild immediate symptoms after a puff, odds ratios were 0.6 (95\% CI 0.1-2.9), 1.2 (95\% CI 0.3-5.6) and 1.07 (95\% CI $0.2-4.5)$ for $1-5$ puffs, 6-10 and $>10$ puffs,

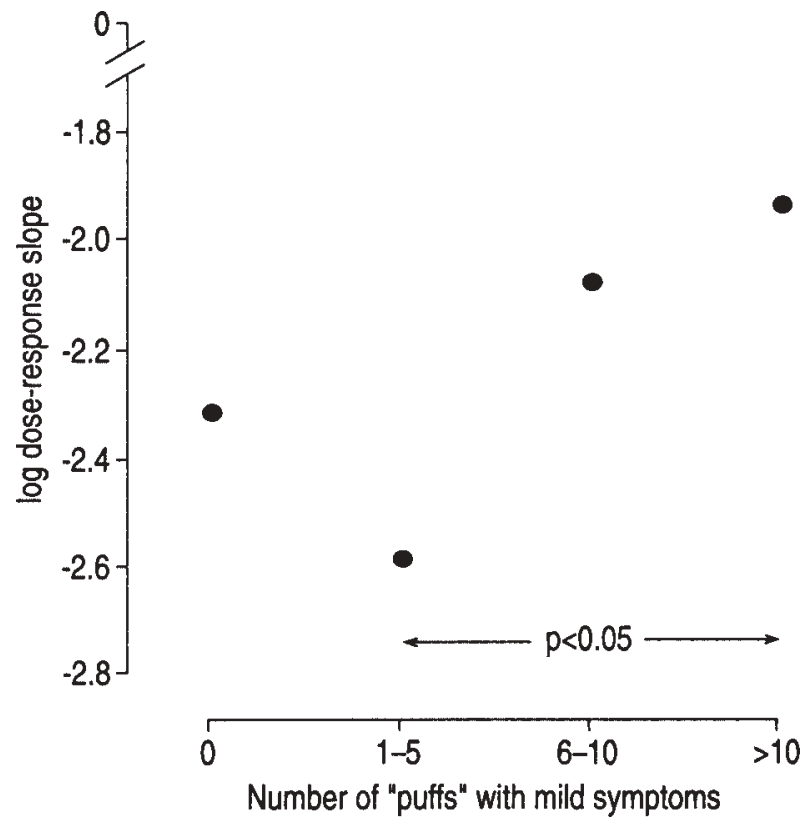

Fig. 2. - Changes in bronchial responsiveness, expressed as log doseresponse slope, with the number of "puffs" with mild symptoms.

Table 4. - Bronchial responsiveness according to reported accidental exposure to chlorine gas, and tobacco use

\begin{tabular}{|c|c|c|c|c|}
\hline & $\mathrm{n}$ & $\begin{array}{c}\mathrm{PC} 20 \\
\leq 16 \mathrm{mg} \cdot \mathrm{mL}^{-1} \\
\mathrm{n}(\%)\end{array}$ & $\begin{array}{c}\text { Measurable } \mathrm{PC}_{20} \\
\leq 32 \mathrm{mg} \cdot \mathrm{mL}^{-1} \\
\mathrm{n}(\%)\end{array}$ & $\begin{array}{c}\text { log dose-response } \\
\text { slope }\end{array}$ \\
\hline \multicolumn{5}{|l|}{ Accident report } \\
\hline None & 204 & $19(9)$ & $31(15)$ & $-2.19 \pm 1.25$ \\
\hline 1 & 27 & 0 & $2(7)$ & $-2.27 \pm 0.8$ \\
\hline$\geq 2$ & 8 & $2(25)$ & $4(50)^{*}$ & $-1.3 \pm 2.4$ \\
\hline \multicolumn{5}{|l|}{ Ever had a "puff" } \\
\hline No symptoms & 45 & $4(9)$ & $6(13)$ & $-2.34 \pm 1.17$ \\
\hline Mild symptoms & 153 & $13(9)$ & $21(14)$ & $-2.19 \pm 1.26$ \\
\hline Sign. symptoms & 38 & $3(8)$ & $8(22)$ & $-1.94 \pm 1.32$ \\
\hline \multicolumn{5}{|c|}{ Number of "puffs" with mild symptoms } \\
\hline 0 & 48 & $6(10)$ & 7 (15) & $-2.30 \pm 1.21$ \\
\hline $1-5$ & 53 & $3(6)$ & 5 (9) & $-2.58 \pm 1.26$ \\
\hline $6-10$ & 35 & $5(14)$ & $6(17)$ & $-2.06 \pm 1.24$ \\
\hline$>10$ & 65 & $5(8)$ & $10(15)$ & $-1.92 \pm 1.22^{\dagger}$ \\
\hline \multicolumn{5}{|c|}{ Year of last symptomatic "puff" } \\
\hline 1992 & 136 & $12(9)$ & $20(15)$ & $-2.09 \pm 1.28$ \\
\hline Before & 100 & $8(8)$ & $15(15)$ & $-2.28 \pm 1.21$ \\
\hline \multicolumn{5}{|c|}{ Previous workplace irritant exposure } \\
\hline None & 84 & $8(10)$ & $16(19)$ & $-2.07 \pm 1.24$ \\
\hline Yes & 155 & $13(8)$ & $20(13)$ & $-2.22 \pm 1.27$ \\
\hline \multicolumn{5}{|l|}{ Smoking habits } \\
\hline Nonsmoker & 108 & $12(11)$ & $19(18)$ & $-2.19 \pm 1.32$ \\
\hline Smoker (ever) & 131 & $9(7)$ & 17 (13) & $-2.15 \pm 1.22$ \\
\hline$<20$ pack-yrs & 200 & $4(11)$ & $28(14)$ & $-2.25 \pm 1.30$ \\
\hline$\geq 20$ pack-yrs & 37 & 17 (9) & $9(24)$ & $-1.72 \pm 1.0^{\ddagger}$ \\
\hline
\end{tabular}

PC20: concentration of methacholine provoking a $20 \%$ reduction in forced expiratory volume in one second. $*$ : $\mathrm{p}<0.05$ in $\mathrm{Chi}^{2}$ test overall and in Fisher's test comparing $\geq 2$ to "None" or $1 ;{ }^{\dagger}: \mathrm{p}<0.05$ in analysis of variance comparing $>10$ to $1-5$; ${ }^{\ddagger}$ : comparing $\geq 20$ to $<20$. 
repectively. In multivariate analysis, the slight doseresponse effect of the intensity of immediate symptoms following a puff on hyperresponsiveness remained nonsignificant when comparing having had immediate significant symptoms versus no symptoms following a puff, after controlling for smoking, year of last puff, or previous irritant exposure. When the analysis was restricted to workers with no current asthma $(n=230)$, similar odds ratios were obtained.

We analysed bronchial responsiveness according to the presence of current symptoms, and not to acute symptoms after a puff. Hyperresponsiveness was significantly more frequent in workers who mentioned each of the persistent respiratory symptoms under study: wheezing (Chisquared 13.8; $\mathrm{p}<0.001$ ); shortness of breath (Chi-squared $4.9 ; \mathrm{p}<0.05)$; symptoms with smoke (Chi-squared 14.8; $\mathrm{p}<0.001$ ), and symptoms on exercise (Chi-squared 4.1; $\mathrm{p}<0.05)$. Analysis of means of log dose-response curve in relation to the presence of current symptoms also showed a statistically significant difference, except for the presence of shortness of breath ( $t$ value $-1.96 ; p=0.07$ ). In addition, analysis of bronchial responsiveness according to pulmonary function tests was performed: FEV1 and FEV1/ FVC were significantly lower in subjects who exhibited more pronounced airway responsiveness; the four lung function parameters were significantly lower in subjects with a measurable PC20; a significant correlation between pulmonary function tests and the dose-response slope was demonstrated.

\section{Air monitoring}

Measured levels of chlorine were generally below the threshold limit value-time weighted average (TLVTWA) and TLV-ceiling (TLVC) recommended by the American Conference of Governmental Industrial Hygienists (0.5 and $1 \mathrm{ppm}$, respectively). For area monitoring, levels exceeded the TLVC only in one sample analysis, during $5.76 \%$ of the registration time (maximum level $1.8 \mathrm{ppm}$ ). For personal monitoring, TLVC was exceeded in 3 out of the 6 samples: during $0.37 \%$ (maximum $4.4 \mathrm{ppm}$ ), $0.04 \%$ (maximum $1.2 \mathrm{ppm}$ ) and $0.72 \%$ (maximum $2 \mathrm{ppm}$ ) of the registration time.

\section{Discussion}

Two conclusions can be drawn from our cross-sectional study, which explored respiratory symptoms, pulmonary function tests and airway responsiveness in workers who experienced accidental inhalation of chlorine over a 3 year period. Firstly, persistent symptoms were not associated with exposure. Secondly, lung function tests and airway responsiveness are slightly but significantly different in workers who experienced immediate symptoms following acute chlorine exposure. In addition, a relationship was found both between reported current respiratory symptoms and lower pulmonary function test values, and a lower threshold in airway responsiveness.
The chronic respiratory effects of environmental chlorine exposure have been studied in two situations: as a consequence of an acute unique accidental exposure and as related to chronic exposure at low levels. Acute unique exposure usually occurs secondary to a storage leak $[5,6$, 20, 21]. Case studies generally show clinical and pulmonary function recovery within 3 months following such an exposure. However, KAUFMAN and BURKONS [22] followed 18 subjects for up to one year after exposure to chlorine from a storage leak and found persistent abnormalities. Only one out of 13 exposed neighbours and passers-by had lasting respiratory abnormalities; in contrast, four of the five chlorine plant workers showed persistent lung function impairment. These workers reported previous symptomatic chlorine exposure at the workplace. ScHWARTZ et al [6] were the first to examine airway responsiveness 12 yrs after accidental chlorine inhalation in 13 subjects; they found persistent hyperresponsiveness in five of them.

Chronic exposure to chlorine is only occupational. Such chronic exposure at low levels is usually combined with repeated accidental short-term inhalations. A few epidemiological studies have been conducted in pulpmills and papermills [10-12]. In these studies, the frequency of respiratory symptoms and spirometry were assessed. Persistent respiratory symptoms were present slightly but significantly more often in workers selfreporting an accidental exposure in the study by KENNEDY and co-workers [10]. The same research group studied the first-aid reports of symptomatic accidental inhalations [11]; the relationship between respiratory symptoms and inhalational accidents increased with the risk of exposure (considered as higher for an accidental inhalation leading to first-aid care, in comparison with a solely self-reported accident). In addition, these two studies, together with the recent one conducted by HENNEBERGER et al. [12], showed mild but statistically significant pulmonary function test differences with the exposure levels: KENNEDY and co-workers [10] found lower average values for $\mathrm{FEF} 25-75 \%$ and $\mathrm{FEV} 1 / \mathrm{FVC}$ ratio in nonsmokers and former smokers who reported an acute exposure than in those reporting no exposure. This research group confirmed their findings in a longitudinal study [11], which showed a greater decline in FEV1/ FVC ratio and FEF 25-75\% in workers who registered with the first-aid department for an accidental inhalation. In their study of pulpmill workers, HENNEBERGER et al. [12] found a threeway interaction of cumulative smoking, cumulative pulpmill exposure and inhalational accidents. In our study, significant differences in FVC and FEV1 according to exposure followed by symptoms was shown only in the subgroup of subjects who had ever smoked; however, no significant interaction was found between smoking habits and accidental exposure. One explanation could be the mean age of our workers, which was half that of the workers studied by HENNEBERGER et al. [12]; therefore, the duration of smoking was shorter, making it less likely for a significant effect to be detected. Although there was no statistically significant interaction between symptomatic exposure and smoking, the results of our study support preventive attitudes for smoking cessation. 
The relevance of the lung function abnormalities can be seen in two ways. Lower FEV1 and FEF25-75\% could reflect airway obstruction; this is in accordance with a previous hypothesis made by KENNEDY and co-workers [10] on persistent inflammatory reaction in the small airways induced by chlorine exposure. On the other hand, a decrease in all functional parameters, including FVC, could be related to minimal parenchymal injury. Earlier reports on the respiratory effects of chlorine have focused on the presence of pulmonary oedema, although WEILL et al. [5] were unable to detect long-term functional consequences in a small group of 12 workers.

To the best of our knowledge, airway responsiveness has rarely been assessed in epidemiological studies of workers exposed to chlorine. BHÉRER et al. [7] studied a cohort of construction workers exposed to chlorine in a pulpmill over a 3-6 month period. Seventy one of 289 exposed workers $(25 \%)$ reported persistent shortness of breath and/or abnormal lung sounds; assessment of airway responsiveness 18-24 months after the end of exposure revealed a $\mathrm{PC} 20$ below $16 \mathrm{mg} \cdot \mathrm{mL}^{-1}$ in 29 of the 71 workers (41\%). KERN [23] demonstrated a dose-response effect between exposure level and the occurrence of respiratory symptoms and hyperresponsiveness, consistent with the diagnosis of RADS, among community hospital workers acutely exposed to another airway irritant, glacial acetic acid.

In our study, hyperresponsiveness was not more frequent with increasing levels of exposure; in contrast to our hypothesis, assessment of hyperresponsiveness does not appear to be more sensitive than spirometry in detecting early respiratory abnormalities in chlorine-exposed workers. However, we did observe a slight but significant decrease in the threshold of airway responsiveness with the same exposure variables. Moreover, in the small group of workers who reported two or more gassing accidents to the first-aid unit, there was a significantly higher proportion with a measurable PC20 as compared with those reporting none, a finding corroborated in the comparison of the dose-response slope, although a significant difference was not found between the groups in this instance. Therefore, assessment of hyperresponsiveness appears to be more sensitive than spirometry if repetitive severe incidents occur. This result can be seen in two ways: on the one hand, changes in airway responsiveness could be attributable to chlorine exposure; on the other hand, a decrease in threshold of airway responsiveness could be due to a prior underlying condition predisposing the subjects to respiratory abnormalities after exposure. To consider chlorine exposure as a causal factor is in agreement with the functional results of our study, suggesting either mild airway abnormalities or minimal parenchymal injury. In this respect, changes in airway responsiveness are known to be related primarily to asthma, but they can also be seen, although not as consistently and not to the same degree, in other diseases with parenchymal involvement [24].

In contrast to previous findings by KENNEDY and co-workers [10], we did not find any difference in persistent respiratory symptoms with varying levels of chlorine exposure. We think it unlikely that the questionnaire applied [13], which is commonly used in epidemiological studies, lacked sensitivity; in fact, the low percentage of currently symptomatic workers reflects the respiratory test findings. As differences in respiratory function tests and airway responsiveness, although significant, were mild, these may reflect subclinical airway abnormalities.

There is no evidence from the results presented here that new cases of RADS occurred as a result of accidental exposure to chlorine at high concentrations. However, we hypothesize that these exposures may cause a subclinical form of RADS, and that some workers may develop RADS as a result of multiple exposure to puffs with significant symptoms.

Possible biases should be addressed. In this instance, three sources of error can be discussed: information bias, selection bias and confounding. Information bias might have resulted both from recall and overreporting biases. Both could have been introduced in the self-reported occurrence of accidental exposure as well as immediate symptoms. However, the study of first-aid accident reports showed that only three workers reporting an acute inhalation with immediate significant symptoms did not report for first-aid care. We cannot discount the possibility that acute inhalation with mild symptoms would be more difficult to remember. However, the fact that only objective indices of respiratory function were significantly different according to the number of puffs with mild symptoms, and not the reported current symptoms, strongly argues against these biases; workers with current respiratory symptoms did not appear more likely to recall accidental exposure or to mention one, even if it had not occurred. It could also be argued that workers with baseline hyperresponsiveness may be more aware of exposure and may experience more severe and more frequent immediate symptoms, and, therefore, the estimate of exposure based on self-reported puffs with or without significant symptoms may be biased. However, other investigators have also used questionnaire-reported incidents or first-aid reports to evaluate exposure if objective measures are not available $[10,11]$. To account for this possible bias, we controlled for personal asthma in multivariate analysis. Selection biases appear negligible: on the one hand, the great majority of workers at risk participated in the study, and only three acutely exposed subjects who registered with first-aid left the factory within the 3 year exposure period before the beginning of the study. The higher proportion of reported gassing incidents among nonparticipants than among participants could suggest a bias; however, this difference was not significant. On the other hand, one cannot eliminate a previous selection at the time of appointment. Finally, control for asthma and tobacco intake takes into account possible confounding factors.

Although we describe an association between acute chlorine inhalation and small changes in lung function as well as a mild increase in airway responsiveness, we cannot with certainty attribute these changes to exposure, given the cross-sectional design of the study. An ongoing prospective study at the same workplace will enable us to relate intraindividual changes to a history of puffs during the follow-up period. 
Our study focused on acute accidental inhalations and their characteristics, which defined the level of exposure. The respective roles ascribed to chronic exposure at a low level and to acute accidental inhalations in respiratory abnormalities have not been ascertained. Further longitudinal studies should help in better understanding these occupational hazards.

Acknowledgements: The authors wish to thank the employer and the workers whose willing co-operation made the study possible, the medical technologists, L. Cyr Dufour and H. O'Grady, who administered the respiratory function tests, K. Tallman and L. Schubert, who reviewed the manuscript.

\section{References}

1. Berghoff RS. The more common gases; their effect on the respiratory tract. Arch Intern Med 1919; 24: 678-684.

2. Black JE, Glenny ET. Observations on 685 cases of poisoning by noxious gases used by the enemy. $\mathrm{Br} \operatorname{Med} J$ 1915; 2: 165-167.

3. Das R, Blanc PD. Chlorine gas exposure and the lung: a review. Toxicol Ind Health 1993; 9: 439-455.

4. Chasis H, Zapp JA, Bannon JH, et al. Chlorine accident in Brooklyn. Occup Med 1947; 4: 152-170.

5. Weill H, George R, Schwartz M, Zuskind M. Late evaluation of pulmonary function after acute exposure to chlorine gas. Am Rev Respir Dis 1969; 99: 374-379.

6. Schwartz DA, Smith DD, Lakshminarayan S. The pulmonary sequelae associated with accidental inhalation of chlorine gas. Chest 1990; 97: 820-825.

7. Bhérer L, Cushman R, Courteau JP, et al. A survey of construction workers repeatedly exposed to chlorine over a 3-6 month period in a pulpmill. II. Follow-up of affected workers with questionnaire, spirometry and assessment of bronchial responsiveness 18-24 months after exposure ended. Occup Environ Med 1994; 51: 225-228.

8. Brooks SM, Weiss MA, Bernstein IL. Reactive airways dysfunction syndrome (RADS): persistent asthma syndrome after high level irritant exposures. Chest 1985; 88: 376-384.

9. Brooks SM, Bernstein IL. Reactive airways dysfunction syndrome or irritant-induced asthma. In: Asthma in the Workplace. Bernstein IL, Chan-Yeung M, Malo JL, Bernstein DI, eds. New York, Marcel Dekker Inc., 1993; pp. 533-549.

10. Kennedy SM, Enarson DA, Janssen RG, Chan-Yeung M. Lung health consequences of reported accidental chlorine gas exposures among pulpmill workers. Am Rev Respir Dis 1991; 143: 74-79.
11. Salisbury DA, Enarson DA, Chan-Yeung M, Kennedy SM. First-aid reports of acute chlorine gassing among pulpmill workers as predictors of lung health consequences. Am J Ind Med 1991; 20: 71-81.

12. Henneberger PK, Ferris BG Jr, Sheehe PR. Accidental gassing incidents and the pulmonary function of pulpmill workers. Am Rev Respir Dis 1993; 148: 63-67.

13. Burney PGJ, Chinn S, Britton JR, Tattersfield AE, Papacosta AO. What symptoms predict the bronchial response to histamine? Evaluation in a community survey of the bronchial symptoms questionnaire (1984) of the International Union Against Tuberculosis and Lung Disease. Int J Epidemiol 1989; 18: 165-173.

14. American Thoracic Society. Standardization of spirometry: 1987 Update. Am Rev Respir Dis 1987: 136: 1285-1307.

15. Knudson RJ, Lebowitz MD, Holberg CJ, Burrows B. Changes in the normal maximal expiratory flow-volume curve with growth and aging. Am Rev Respir Dis 1983; 127 : 725-734.

16. Cockcroft DW, Murdock KY, Mink JT. Determination of histamine PC20. Chest 1983; 84: 505-506.

17. Sterk PJ, Fabbri LM, Quanjer PH, et al. Airway responsiveness: standardized challenge testing with pharmacological, physical and sensitizing stimuli in adults. Report working party standardization of lung function tests. European Coal and Steel Community. Official statement of the European Respiratory Society. Eur Respir J 1993; 6 (Suppl. 16): 53-83.

18. Malo JL, Pineau L, Cartier A, Martin RR. Reference values of the provocative concentrations of methacholine that cause $6 \%$ and $20 \%$ changes in forced expiratory volume in one second in a normal population. Am Rev Respir Dis 1983; 128: $8-11$.

19. O'Connor G, Sparrow D, Taylor D, Segal M, Weiss S. Analysis of dose-response curves to methacholine: an approach suitable for population studies. Am Rev Respir Dis 1987; 136: 1412-1417.

20. Hasan FM, Gehshan A, Fuleihan FJD. Resolution of pulmonary dysfunction following acute chlorine exposure. Arch Environ Health 1983; 38: 76-80.

21. Jones RN, Hughes JM, Glindmeyer H, Weill H. Lung function after acute chlorine exposure. Am Rev Respir Dis 1986; 134: 1190-1195.

22. Kaufman J, Burkons D. Clinical, roentgenologic and physiologic effects of acute chlorine exposure. Arch Environ Health 1971; 23: 29-34.

23. Kern DG. Outbreak of the reactive airways dysfunction syndrome after a spill of glacial acetic acid. Am Rev Respir Dis 1991; 144: 1058-1064.

24. Malo JL, Tessier P. Airway hyperresponsiveness and asthma. In: O'Byrne PM, eds. Asthma as an Inflammatory Disease. New York, Marcel Dekker, 1990; pp. 71-102. 